\title{
Bài 88 - Văn hóa doanh nghiệp thời kì mới
}

\author{
Duy Long
}

Báo Tuổi Trẻ Thủ Đô

October 5, 2017

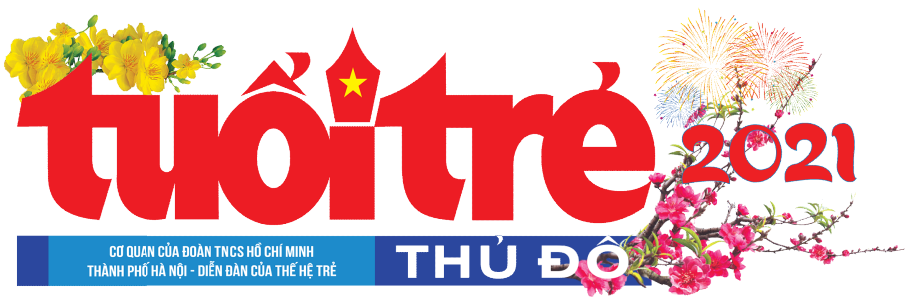

https://tuoitrethudo.com.vn/bai-88-van-hoa-doanh-nghiep-thoi-ki-moi-79564.html 


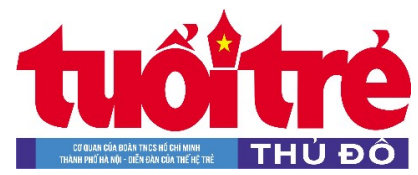

\section{Bài 88: Văn hóa doanh nghiệp thời kì mới}

15:18|05/10/2017

TTTĐ.VN - Việc hội nhập ASEAN tạo ra tiềm năng lớn để các nước có thể chuyển dịch cơ cấu và phát triển kinh tế như cơ hội về mở rộng xuất nhập khẩu, đầu tư, chia sẻ học tập kinh nghiệm xây dựng an sinh xã hội nhằm đảm bảo phát triển bền vững. Với quy mô nguồn nhân lực dồi dào và cơ cấu dân số vàng, người lao động lại được đánh giá cần cù, chăm chỉ, thông minh... Việt Nam sẽ hướng tới nâng cao chất lượng lao động đáp ứng hội nhập.

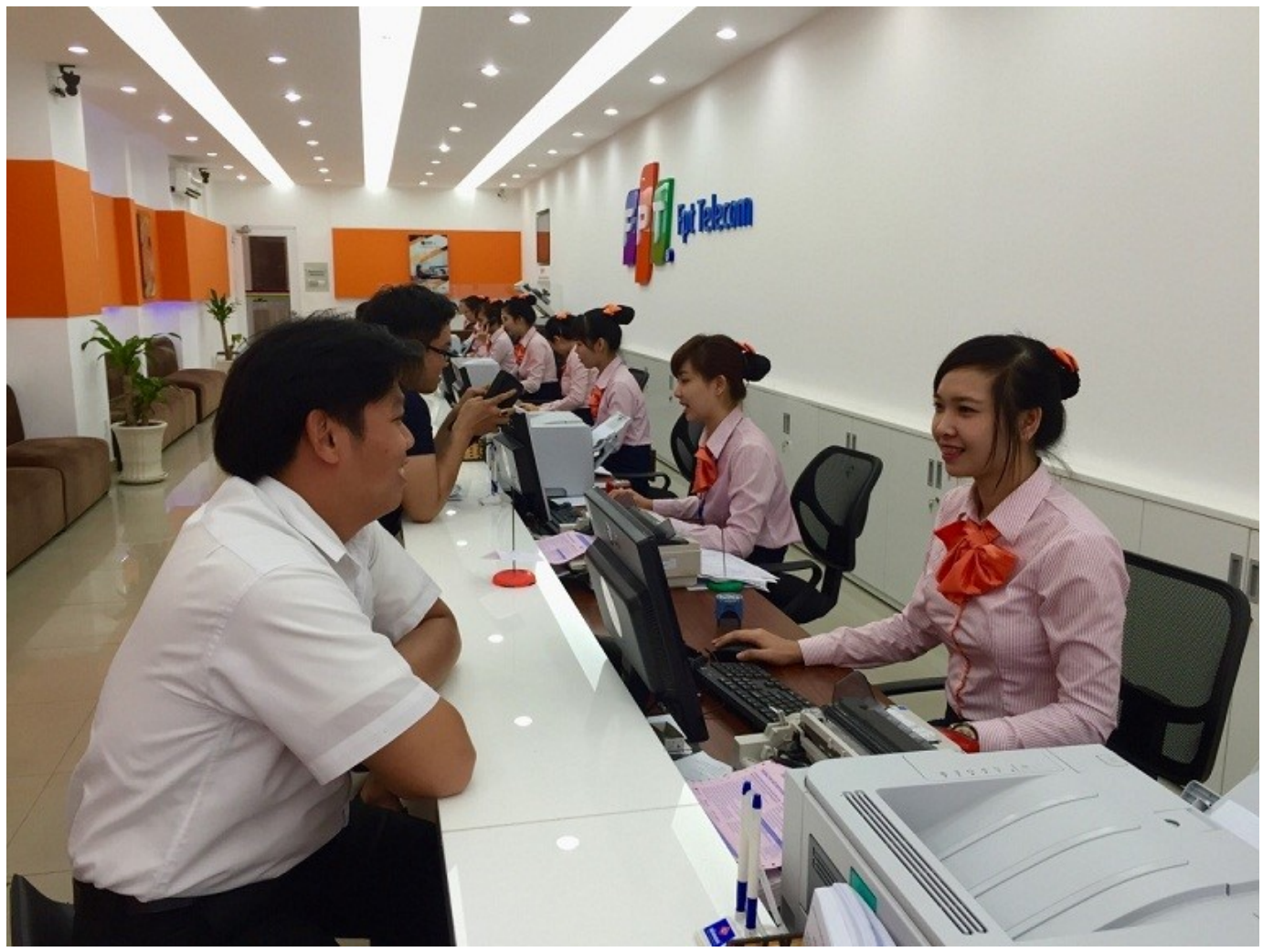

>> Thanh niên với vấn đề hội nhập - Khát vọng vươn xa

Bài 87: Nâng cao chất lượng lao động đáp ứng hội nhập

VHDN có khởi nguồn từ nước Mỹ, sau đó được Nhật Bản xây dựng và phát triển mạnh mẽ. Tuy nhiên, VHDN phải bám sâu vào nền văn hóa dân tộc mới phát huy được tối đa hiệu quả. Nhận thức được tầm quan trọng của mối quan hệ giữa VHDN với bản sắc văn hóa dân tộc, khái niệm văn hóa giao thoa đã được hình thành. Theo đó, các công ty đa quốc gia luôn biết kết hợp lợi ích của mình với VHDN của nước chủ nhà.

Có nhiều quan điểm, khái niệm khác nhau về VHDN nhưng về tổng thể, phạm trù này có thể hiểu là sự tổng hòa của quan niệm giá trị, tiêu chuẩn đạo đức, triết lí kinh doanh, quy phạm hành vi, ý tưởng kinh doanh, phương thức quản lí... được toàn thể thành viên trong doanh nghiệp chấp nhận, tuân theo. VHDN lấy việc phát triển toàn diện con người làm mục tiêu cuối cùng. Cốt lõi của VHDN là tinh thần doanh nghiệp và quan điểm giá trị của doanh nghiệp.

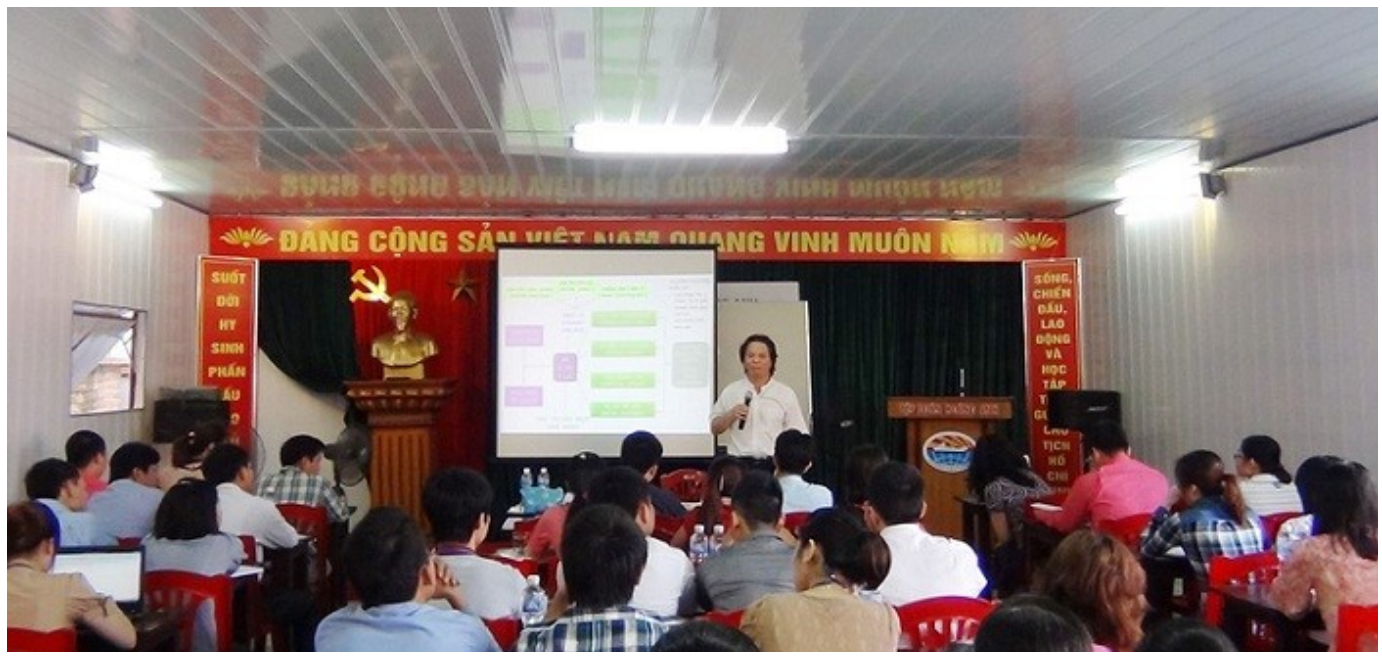




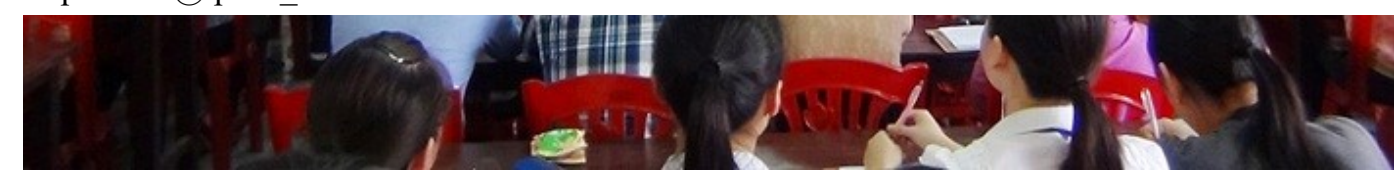

Tập đoàn Hoàng Anh (Hải Phòng) tổ chức buổi tập huấn nhận thức về VHDN cho Ban lãnh đạo và cán bộ, nhân viên

Trong quá trình phát triển, mỗi doanh nghiệp đều nỗ lực xây dựng một hệ thống quan điểm, giá trị cho riêng mình. VHDN là một giai đoạn phát triển của tư tưởng quản lí doanh nghiệp hiện đại, thể hiện sự chuyển dịch chiến lược kĩ thuật, nhằm tạo nên những sản phẩm hàm chứa hàm lượng văn hóa cao. Bởi vậy, có thể coi VHDN là yếu tố cực kì quan trọng của thực tiễn doanh nghiệp đương đại.

Bên cạnh những yếu tố như sản phẩm, thị trường, công nghệ, năng lực kinh doanh thì VHDN được coi là nguồn lực, là yếu tố quan trọng quyết định sự thành công của các doanh nghiệp. Xây dựng VHDN, văn hóa doanh nhân đóng vai trò quan trọng trong sự phát triển bền vững của đất nước.

Những năm gần đây, nhiều doanh nghiệp Việt Nam đã rất quan tâm đến việc xây dựng VHDN, thậm chí có những doanh nghiệp không hề tiếc tiền mời các công ty nước ngoài đến hoạch định VHDN cho công ty mình. Học tập VHDN tiên tiến nước ngoài đã trở thành tư duy mới của các doanh nghiệp Việt Nam hiện nay. Đặc biệt, sự kiện Việt Nam gia nhập Tổ chức Thương mại thế giới (WTO), đất nước đã hội nhập ngày càng sâu, rộng hơn vào nền kinh tế toàn cầu. Đó là một lời mời không thể khước từ "luật chơi" nghiệt ngã của thương trường trong nước và quốc tế: cạnh tranh và đào thải. Điều đó đòi hỏi giới doanh nhân Việt Nam phải nhanh chóng hoàn thiện nhân cách, trí tuệ, sự đoàn kết, đồng lòng; xây dựng cộng đồng doanh nghiệp mạnh mẽ, với hành trang "văn hóa kinh doanh Việt Nam" vững vàng, chủ động, sẵn sàng trước những thách thức mới.

Sản phẩm có hàm lượng văn hóa cao sẽ hấp dẫn và có sức cạnh tranh. Những doanh nghiệp nổi tiếng, những doanh nhân xuất sắc bao giờ cũng dành trí tuệ cho việc xây dựng và phát triển chiến lược và triết lý kinh doanh của riêng mình. Xây dựng năng lực cạnh tranh và tìm kiếm lợi nhuận phải tuân thủ mục đích xã hội, không thể làm giàu bằng mọi giá mà gây tổn thương tới xã hội, làm suy thoái đạo đức, tàn phá môi trường.

Mỗi nền văn hóa khác nhau đều đưa đến nhận thức khác nhau và tác động đến hệ thống VHDN khác nhau. ở Nhật Bản, những người lao động thường làm việc suốt đời cho một công ty, họ được xếp hạng theo trình độ tay nghề và bề dày công tác. Chính VHDN kiểu Nhật Bản đã tạo cho doanh nghiệp một không khí làm việc dựa trên cơ sở quan hệ với các thành viên như trong một gia đình, họ gắn bó với nhau chặt chẽ trong quá trình làm việc và sinh hoạt. Lãnh đạo doanh nghiệp luôn quan tâm đến các thành viên về mọi mặt, cả về vật chất và tinh thần. Người lao động được tạo điều kiện để học hỏi và đào tạo từ nguồn vốn của doanh nghiệp.

Trên thế giới và ngay cả ở Việt Nam rất nhiều doanh nghiệp đề cao chữ tín, giữ gìn uy tín, thương hiệu của mình, ứng xử trách nhiệm với khách hàng. Đó là việc các hãng sản xuất ô tô Nhật Bản sẵn sàng thu hồi để khắc phục hàng triệu sản phẩm có lỗi kỹ thuật.

Volkswagen thu hồi gần 5 triệu xe ô tô tại Trung Quốc vì lỗi túi khí. Mới đây, hãng Samsung Hàn Quốc cũng cho thu hồi tất cả sản phẩm điện thoại di động Samsung Galaxy Note 7 trên toàn cầu vì lỗi gây nguy hiểm cho khách hàng... Họ đã coi phát triển bền vững, ứng xử văn minh với người tiêu dùng không chỉ là nguyên tắc hành động, triết lí kinh doanh mà còn là yếu tố quyết định thành bại trên thương trường.

Bên cạnh đó cũng xuất hiện không ít doanh nghiệp, doanh nhân còn xem nhẹ chữ tín, vi phạm pháp luật, chạy theo lợi nhuận thuần túy. Những doanh nghiệp này đã cố tình sản xuất thực phẩm bẩn làm hại sức khỏe người dân; nhiều cơ sở kinh doanh hàng nhái, hàng giả, chộp giật, lừa đảo gây thiệt hại lớn cho người tiêu dùng... Đó là những hành vi rất đáng bị lên án và cần phải đào thải.

Cách đây không lâu, một hãng sản xuất đồ uống giải khát trong nước khi bị người tiêu dùng phản ánh rằng trong chai nước uống của hãng có vật thể lạ. Người tiêu dùng đó cho rằng phải được bồi thường. Thay vì cần có sự cầu thị, kiểm tra lại toàn bộ dây chuyền sản xuất thì ông chủ hãng nước ngọt này đã "bài binh, bố trận" giăng bẫy để đưa người tiêu dùng kia vào vòng lao lí với tội danh tống tiền. Kết quả là hãng nước ngọt đó bị đông đảo người tiêu dùng tẩy chay, họ chia sẻ nỗi bất bình trên khắp các trang mạng xã hội. Doanh nghiệp đó đã nhận được một bài học rất đau đớn, chỉ vì mục đích kinh tế trước mắt mà coi nhẹ cách hành xử văn hóa gây dựng thương hiệu lâu dài.

Trong bối cảnh hội nhập kinh tế thế giới ngày một sâu rộng, Việt Nam cần chú trọng xây dựng VHDN, văn hóa doanh nhân với ý thức tôn trọng pháp luật, giữ gìn uy tín, đạo đức kinh doanh và cạnh tranh lành mạnh; góp phần xây dựng cộng đồng phát triển bền vững. Nhà nước cần có cơ chế chính sách, các văn bản quy phạm pháp luật quy định về VHDN, văn hóa doanh nhân. Đặc biệt, cộng đồng doanh nghiệp, mỗi doanh nghiệp không chỉ phấn đấu xây dựng được đội ngũ hùng hậu những nhà kinh doanh có tài, những thương hiệu sản phẩm uy tín, tạo ra sức mạnh kinh tế cho đất nước mà còn phải trở thành những nhà quản lí giỏi, có trách nhiệm xã hội, tâm huyết với đất nước và dân tộc. Văn hóa doanh nhân phải góp phần tạo nên tâm hồn, khí phách và bản lĩnh của lớp doanh nhân Việt Nam trong thời đại mới. 
Bất kỳ một doanh nghiệp nào nếu thiếu đi yếu tố văn hóa, tri thức thì khó đứng vứng được. VHDN là văn hóacủa một tổ chức vì vậy nó không đơn thuần là văn hoá giao tiếp hay văn hoá kinh doanh như ta thường nghĩ. VHDN không phải là những khẩu hiệu của ban lãnh đạo được treo trước cổng, trên hành lang hay trong phòng họp. Đó chỉ là ý muốn, ý tưởng. Những gì chúng ta mong muốn có thể rất khác với những giá trị, niềm tin, chuẩn mực được thể hiện trong thực tế và trong các hành vi mỗi thành viên doanh nghiệp.

Cốt lõi của VHDN là tinh thần doanh nghiệp và quan điểm giá trị của doanh nghiệp. Trong cuốn sách "Văn mình làm giàu và nguồn gốc của cải” của TS. Vương Quân Hoàng đã được đề cập tới khái niệm giá trị. Giải thích một cách đơn giản, giá trị là một cái gì đó mà người ta cảm thấy quan trọng, có ích. Cụm từ "quan trọng" và "có ích lợi" rất đáng lưu tâm trong xây dựng văn hóa doanh nghiệp. Bởi lẽ lãnh đạo công ty sẽ rất khó xây dựng văn hóa doanh nghiệp, nếu không truyền đạt được những ích lợi mà văn hóa doanh nghiệp đem lại. Nhân viên cần được giáo dục nhận thức rằng việc đeo thẻ nhân viên, mặc đồng phục là thể hiện sự tự hào là thành viên của công ty và có ích cho công việc của họ chứ không phải họ mang những thứ đó để làm quảng cáo.

(còn nữa)

Duy Long

Đường dẫn bài viết: https://tuoitrethudo.com.vn/bai-88-van-hoa-doanh-nghiep-thoi-ki-moi-79564.html

Bản quyền thuộc https://tuoitrethudo.com.vn/

In bài viết 
Tài liệu tham khảo:

[1] Đào Duy Anh. (1938). Việt Nam văn hóa sử cương. Quan Hải Tùng Thư, Huế (Imprimerie du Mirador).

[2] Vương Quân Hoàng. (2007). Văn minh làm giàu \& Nguồn gốc của cải. Nxb Chính trị Quốc gia, Hà Nội. 